UDC 101.1

LBC 87.25

\title{
POSSIBILITIES OF DEVELOPMENT TECHNOLOGIES OF CONTEMPORARY SCIENCE SUBJECT: PHILOSOPHICAL GROUNDS AND REGULATORY REQUIREMENTS
}

\author{
Oleg S. Smoligovets \\ Volgograd State University, Volgograd, Russian Federation
}

\begin{abstract}
The paper suggests the search for ways of development of modern science subject in the context of post-non-classical scientific rationality. The logic of the functioning of science as a system assumes that the activities of the subjects perform the regulatory function of the whole system. The development of the subject of science appears as a systemic problem, which includes not only professional development, but also the formation of multidimensional responsibility of scientists, which is manifested both in the interaction of science and society, and in the processes taking place within the science itself.

The subject of technological impact is not an individual scientist or a team, but an integrated system, which is the science itself. The author concludes that such a system should have the status of a subject (metasubject), since its effects on scientists are manifested not as a determination, but as the opening of the space of freedom, the preservation of uncertainty in the system. Social technologies are relied upon as a mechanism for the formation and maintenance of metasubject status of science. Social technologies are supposed to be extremely flexible, because in the semantic space of science as a subject there is a higher level of freedom and subjectivity. The key technological requirement here is the growth of autonomy of the subject, which voluntarily and interestedly moves into the sphere of metasubject science. The potential of such a subject implies the requirement to identify the hidden potential of the system state. The notion of metasubject denotes a higher level of subjectivity than individuals and groups (subjects in the traditional sense). Metasubject acts as a source of space of scientific intersubjectivity. As a fundamental requirement for the activity of the subject of science the author points out the need to update the solution of strategic tasks on a par with the current ones. Taking into consideration all the stated above the study specifies a number of post-non-classical rationality norms: cognition is understood as a subject-subject process; reflection on the value measurement of knowledge is assumed; the self-developing nature of cognizable systems is postulated; the necessity of correlation of three forms of subjectivity in science (personality, collective, Institute); the communicative basis of human existence, the need to rely on the principle of cooperation is realized; understanding is fixed as a method of modern science; the nature of the connection between fundamental and applied research is clarified; the requirement of the analysis of knowledge riskiness is put forward.
\end{abstract}

Key words: science, technology, subject, post-non-classical rationality, intersubjectivity.

\section{О ВОЗМОЖНОСТИ ТЕХНОЛОГИЙ РАЗВИТИЯ СУБЪЕКТА СОВРЕМЕННОЙ НАУКИ: ФИЛОСОФСКИЕ ОСНОВАНИЯ И НОРМАТИВНЫЕ ТРЕБОВАНИЯ

\author{
Олег Сергеевич Смолиговец
} \\ Волгоградский государственный университет, г. Волгоград, Российская Федерация \\ Аннотация. В данной статье осуществляется поиск путей развития субъекта современной науки в контексте постнеклассической научной рациональности. Логика функционирования науки как системы пред-}


полагает, что деятельность субъектов исполняет по отношению к ней регулятивную функцию. Развитие субъекта науки предстает в качестве системной задачи, включающей не только повышение профессиональной квалификации, но и формирование многоаспектной ответственности ученых, которая проявляется как во взаимодействии науки и общества, так и в процессах, происходящих внутри самой науки. Предметом технологического воздействия становится не отдельный ученый или коллектив, а целостная система, которой является сама наука. Делается вывод о том, что такая система должна иметь статус субъекта (метасубъекта), поскольку ее воздействия на ученых проявляются не как детерминация, но как открытие пространства свободы, сохранение неопределенности в системе.Социальные технологии полагаются в качестве механизма формирования и поддержания метасубъектного статуса науки. Социальные технологии полагаются как предельно гибкие, потому что в смысловом пространстве науки как субъекта заключен более высокий уровень свободы и субъективности. Ключевым технологическим требованием здесь выступает рост автономии субъекта, который добровольно и заинтересованно переходит в сферу метасубъекта науки. Потенциал такого субъекта предполагает требование выявления скрытого потенциала состояния системы. Понятие метасубъекта обозначает более высокий уровень субъектности, нежели индивиды и коллективы (субъекты в традиционном смысле). Метасубъект выступает как пространство научнойинтерсубъективности. В качестве фундаментального требования к деятельности субъекта науки выделяется необходимость актуализации решения стратегических задач наравне с текущими. Кроме того, был уточнен ряд норм постнеклассической рациональности: познание рассматривается как субъект-субъектный процесс; предполагается рефлексия относительно ценностного измерения получаемого знания; постулируется саморазвивающийся характер познаваемых систем; утверждается необходимость соотношения трех форм субъектности в науке (личности, коллектива, института); осознается коммуникативная основа бытия человека, вводится принцип сотрудничества; закрепляется понимание как метод современной науки; утверждается связь фундаментальных и прикладных исследований, технологизация; выдвигается требование анализарискогенности знания.

Ключевые слова: наука, технология, субъект, постнеклассическая рациональность, интерсубъьективность.

Современная наука, безальтернативно ставшая основной производительной силой общества, находится в сложных отношениях с субъектами научной деятельности: теперь это уже не простое описание объекта в нормах классической рациональности, в которых субъект сводится лишь к факту его сознания как понятийно-логическому «экрану», никак не воздействующему на предмет исследования. Сегодня нормой взаимодействия науки с объективной реальностью стала постнеклассическая рациональность, в которой субъекты исследуют свои объекты с учетом моральных позиций, культурно-ценностных ориентиров и господствующей в данную эпоху картиной мира. Как отмечает О.Ю. Есина: «[Постнеклассическая] научная рациональность переосмысливает отношение к человеку, осознавая роль деятельностного субъекта как неотъемлемой части социальной действительности, с которой он взаимодействует напрямую» [4, с. 37]. Поэтому науке для сохранения своей объективности важным становится соответствие ее собственного бытия в обществе тех свойств субъектов науки, которые обеспечивают и сохраняют это соответствие.

С. Тулмин, известный представитель современной философии науки, отмечает: «На- ука, рассматриваемая в качестве целостной человеческой инициативы, не является ни только компендиумом идей и аргументов, ни только системой институтов заседаний. В тот или иной момент интеллектуальная история научной дисциплины, институциональная история научной специальности и индивидуальных биографий ученых, очевидно, соприкасаются, взаимодействуют друг с другом... Следовательно, дисциплинарные (или интеллектуальные) и профессиональные (или человеческие) аспекты науки должны быть тесно взаимосвязанными, но ни один из них не может быть полностью первичным или вторичным по отношению к другому» [11, с. 305-306]. Как утверждает В.С. Степин, «стратегию развития современной (постнеклассической) науки определяет освоение сложных, саморазвивающихся систем» [10]. В этом целостном пространстве (или системе) бытия науки «слабым звеном» оказываются ее субъекты: выступая как конкретный научный коллектив, им приходится решать не только сами научно-исследовательские задачи, но и постоянно учитывать те возможные негативные последствия для общества, которые могут вызвать полученные результаты. Безупречные в чисто логическом плане, эти результаты мо- 
гут воздействовать на общество как источник новых рисков и опасностей. По словам Р. Мертон, «нравы науки имеют методологическое рациональное оправдание, однако обязывающими они являются не только в силу своей процедурной эффективности, но и потому, что считаются правильными и хорошими» [6, с. 770]. Поэтому возникает новая функичия - развитие субъектов современной на$y к u$, направленная на особую дополнительную «социализацию» этих субъектов, то есть на формирование их способности видеть и устанавливать формы «человеческого измерения» результатов научных исследований - социальные, моральные, экологические, культурные и др.

Здесь не имеется в виду очевидная задача постоянного повышения собственной профессиональной квалификации исследователей, хотя эти аспекты, конечно, включены в содержание рассматриваемой проблемы развития субъектов науки. Главное для нас формирование сочиальной, моральной, профессиональной и гражданской ответственности ученых, которая возникает закономерно на основе освоения и осознания исследователями и их коллективами как сложности взаимодействия науки и общества, так и многомерности самой науки как системы. Возникает задача входа субъектов науки в особое пространство, в котором осуществляется их культурная, социальная, моральнонравственная «социализация».

Формирование такого пространства весьма сложная задача, так как в нем должны существовать некоторые смыслы и реалии, способные воздействовать на сознание и установки субъектов науки, то есть изменять это сознание и его содержание. Но это значит, что в данных смыслах должен заключаться некий более высокий уровень свободы и субъективности, на который добровольно и заинтересованно переходят субъекты, так как не находят его в себе, осознавая потребность в освоении этого уровня: ведь он расширяет горизонт их мировоззрения, свободы, творчества, обеспечивает профессиональный и гражданский рост.

Является ли содержание этого пространства воздействия на субъектов нормативноидеальным, или в нем концентрируется осо- бая объективная реальность - целостность, законы, тенденции, системные связи и т. п., действующая на сознание этих субъектов и его развитие, как особое концентрированное социальное бытие данного общества? Или здесь возникает их взаимодействие?

Прежде всего, выскажем предположение, что воздействие объективного материально и идеально (духовно) на сознание и поведение человека связано с полнотой бытия этих реальностей, которые выходят за рамки их охвата сознанием. В целом, статус такой объективности приобретают и различного вида нормы - социальные, моральные, культурные. Созданные в другие эпохи как стихийно-общественное обобщение разных видов опыта поколений, эти нормы содержат гораздо больше «единиц регулирования» и связей, чем те, которые «попадают» в сознание следующих им субъектов. Информационносмысловое содержание таких норм оказывается для субъектов «избыточным».

Действительно, обычный человек воспринимает любую моральную норму как нечто очевидное. Он не задумывается над тем, что в ней осуществляется процесс огромной сложности: неопределенность содержания в виде массовых хаотических процессов взаимодействий и типов поведения становится определенностью - согласованным поведением этих субъектов, позволяя осуществлять взаимопонимание, коллективные действия, разумное по смыслу общение, а также выделять приоритет общих интересов и норм порядка над любыми частными побуждениями и стремлениями.

Хотя моральные нормы идеальны, они все же остаются объективными, поскольку не существуют в фиксируемом чувствами предметном выражении. Однако есть и материально выраженные объективные процессы: развитие производственных отношений, зависимость общественной жизни и ее организации от роста населения, фундаментальные свойства данной общественно-экономической формации и др. Они воздействуют на сознание субъектов именно как способ существования этих субъектов в обществе. Последние не могут осознанно и радикально конструировать объективность своего бытия, хотя и воздействовуют на условия (выбирют предпочи- 
таемые общественные отношения и развивают их, как бы «блокируя» другие, менее связанные с их интересами и целями), что в результате меняет и сами формы бытия общества. Этот выбор постоянно включен в общее направление видов деятельности, которые выполняют субъекты: он не возникает как специальная задача.

Таким образом, задача развития субъектов науки предполагает создание таких среды или пространства, в которых концентрируются средства воздействия на их сознание, превращающие общество в особый «предмет» постижения для ученых. Этот «предмет» для них открывается как «метасубъект», поскольку начинает регулировать сознание и поведение исследователй, как освоение его собственного содержания и связанных с ним ценностей и смыслов более высокого уровня сложности и объективности. Хороший пример бытия такого метасубъекта приводит Х.-Г. Гадамер в своей концепции языка как источника формирования понимания в процессе общения субъектов: «Человек, живущий в мире, - пишет он, - не просто снабжен языком как некоторой оснасткой - но на языке основано и в нем выражается то, что для человека вообще есть мир... Не только мир является миром лишь постольку, поскольку он получает языковое выражение, - но подлинное бытие только и состоит в том, что в нем выражается мир... Иметь мир - значит иметь отношение к миру. Но отношение к миру требует такой свободы от того, что встречается нам в мире, которая позволила бы нам ставить это встречающееся перед собою таким. Каким оно есть. Эта возможность представления означает одновременно обладание миром и обладание языком» [1, с. 512-513].

В этом случае язык выполнят функцию такого субъекта, который выделяется из реальности (мира) и вместе с тем формирует отношение к миру. Здесь также определенно подразумевается, что восприятие реальности человеком не является «изначальным», но определено языком как особой формой бытия (метасубъекта), в которой нам открывается и сам мир. При этом реальность фиксируется как бы «сквозь» языковые структуры и значения, которые сами по себе не выступают для человека объектом отношения. Они от- крываются в этом аспекте лишь тогда, когда начинают служить препятствием для коммуникации, понимания, или осмысленного восприятия реальности.

Таким образом, отмеченное здесь пространство воздействия на субъекты науки в целях их собственного развития должно иметь статус субъекта, поскольку оно моделирует способность субъекта формировать отношение к реальности и вместе с тем - отделяться от нее. Кроме того, эта способность формирует отношение субъектов к самим себе. Именно в этом плане воздействие субъекта на других субъектов оказывается принципиально иным, чем функционально и на основе смыслов организованной совокупности предметов и их связей воздействие внешней среды. Объекты действуют на субъекты преимущественно как внешняя необходимость, требующая адаптации или учета рамок и характера ее влияния. Но воздействие субъекта - это открытие пространства нового уровня свободы, к которому добровольно и заинтересованно «примыкают» другие субъекты - те, которые воспринимают такое воздействие. Вместе с этой новой свободой возникает и расширение кругозора, понимания, появляется более глубокое самосознание и обязательно развивается чувство ответственности, как осознание последствий реализации приобретенной свободы.

Формирование модели пространства, представляющего уровень метасубъекта сложная задача, требующая включения проектно-обучающей деятельности с аспектами социализации, формирования мировоззрения и культуры и опирающейся на сочиальные технологии. Последние, при всем своем современном разнообразии, до сих пор не имеют однозначного определения и трактовки. Их связывают с формированием цепочки некоторых выделенных «единиц», или алгоритмов, которые позволяют достичь заданных результатов, с исследованием потенциала социального пространства и социальных отношений, с восстановлением балансов в социальном пространстве, рассматривают как средство социального управления и др.

Есть несколько подходов к определению социальных технологий. В дискуссиях относительно соотношений между социальными и 
естественнонаучными технологиями часто прослеживается тенденция в интерпретации социальных технологий как обслуживающих естественнонаучные. В.Г. Горохов утверждает: «Экспериментальные объекты и процессы, воплощаясь в новых технологиях и в хозяйственных структурах, становятся частью социальной реальности и в этом качестве объектами исследования социально-гуманитарных, а не естественных и технических наук» [2, с. 121]. То есть социальная технология - это адаптация естественнонаучной технологии в социокультурном контексте.

Защитники самобытного статуса социальных технологий, как правило, фиксируют предметную специфику последних. В.Н. Иванов и В.И. Патрушев рассматривают социальную технологию как процесс оптимизации социального пространства, преодоления его разбалансированности на основе инновационного метода освоения социальной действительности, активного воздействия на развитие социальных систем с использованием социальных технологий (глобальных, внедренческих, обучающих, информационных и др.), которые позволяют включить в процесс его усвоения не только познание и методы социальной диагностики, но и активные способы его изменения, мотивизации, обучения, инновирования как субъектов управления, так и социальных систем в целом [5, с. 4].

В «Энциклопедическом социологическом словаре» выделяют такие аспекты социальных технологий, как «совокупность приемов, методов и воздействий, применяемых для достижения поставленных целей в процессе социального планирования и развития, решения разного рода социальных проблем» $[9$, c. 372].

Существуют также подходы, говорящие об обратном влиянии гуманитарной и социальной сферы на номотетические науки и исходящие из них технологии. Как справедливо утверждает И.И. Гусева, движение номотетических наук к индивидуализации есть не просто поиск новой «точки сборки», но раскрытие новых горизонтов в изучении социального бытия. «Произошла легитимация индивидных форм социального; для того чтобы исследовать эту вновь открытую конкретность человеческого мира, понадобились другие мето- ды. Так появилась “качественная”, или “гуманистическая”, социология» [3, с. 35].

Несмотря на все эти технологические достижения, возникает вопрос: если субъект представляет собой некоторое целое, не сводимое к совокупности приемов и методов его достижения, каким же образом можно смоделировать его пространство, выражающее такую целостность?

Здесь открывается другая сторона, которая не раскрыта в социальных технологиях, но непосредственно к ним примыкает: внутренняя субъектность текстов, жанров, форм художественной культуры - литературы, искусства и др. Эта субъектность проявляется через используемый язык, в котором выражается позиция автора, мировоззрение и ценности эпохи, типы и мотивы действующих героев и др. Произведения воздействуют на читателя именно потому, что в них выражен «метасубъект» - более высокий уровень субъектной позиции, выступающий как интерсубъективность.

А.П. Огурцов, уточняя содержание концепта интерсубъективности, приходит к пониманию его как континуума перехода между научным творчеством индивида, групповыми представлениями, общественно-признанными фактами и объективированным знанием, причем началом интерсубъективности считается именно микросообщество. Противопоставления исследуемых понятий «объективность», «коллективность» и «интертекстуальность» позволяют глубже понять специфику исследуемого основания субъектности в науке. Противопоставление интерсубъективности и объективности подчеркивает, что знание всегда рождается в коммуникативных взаимодействиях индивидов. Объективное здесь стоит понимать как знание, наделенное статусом существования через сопоставление идеальной объяснительной модели с объективным феноменом или процессом. Противопоставляя интерсубъективность и коллективность, Огурцов не уделяет внимание разграничению коллектива и социального института, по его мнению, все это - проявления коллективности. Более того, в данном вопросе он ограничивается лишь манифестацией: «Необходимо освободить интерсубъективность от отождествления с коллективностью, с солидарным це- 
лым, которое обладает статусом реального существования» [7, с. 242]. Мы согласимся с данным суждением, поскольку неправомерно отождествлять форму бытия субъектов с той средой, которая оформляется на их основе. Противопоставление интерсубъективности и интертекстуальности Огурцова еще раз подчеркивает то, что первая не существует автономно, как некая бессознательная структуpa, вне субъектов, за ним. «Интерсубъективность - это сфера "между", порожденная взаимодействием ученых, не совпадающая ни с интенцией индивидуальных инноваций, ни с объективностью» [7, с. 244].Таким образом, можно сделать выводы о научной интерсубъективности как объединяющей основе развития самого знания и о субъектном основании последнего. Именно интерсубъективность детерминирует связи между формами научной субъектности.

Какова же ее структура? Н.В. Петракова предлагая свою модель структурирования интерсубъективности в творчестве М. Бубера, связывает ее с тремя исследуемыми нами формами субъектности и выделяет три уровня:

1) экзистенциально-феноменологический;

2) культурно-символический;

3) институционально-нормативный $[8$, c. $110-111]$.

Основанием для выделения этих уровней служит характер опосредованности коммуникаций, которые, соответственно, являются не опосредованными, опосредованными языком и опосредованными рыночными механизмами. Приняв эту структуру вне связи с исследованием вышеупомянутого автора, мы видим, что каждый уровень соответствует определенной субъектной форме - личности, группе и институту. Соответственно, логика индивидуального научного творчества, диалога в научном коллективе и следование научным нормативам представляют собой логику построения надындивидуальных связей в научном сообществе, то есть интерсубъективности.

Кроме сложной структуры коллективных субъектов научной деятельности, в построении модели метасубъектного пространства необходимо учитывать те требования к субъектам научного исследования, которые заложены в постнеклассическом типе рациональности. Сюда входит стиль мышления, научная и со- циокультурная картина мира, статус самого процесса познания и науки в обществе и др. Важным требованием также является сохранение истинности получаемых научных результатов, несмотря на сложную интерсубъективную «ткань» взаимодействий индивидов и коллективов с предметом исследования.

Важной задачей социально технологического формирования нового уровня самосознания субъектов науки является личностная и коллективная мировоззренческая позиция, направленная на служение своей стране, на стремление участвовать в решении возникающих здесь проблем. Исследователи должны видеть не только ближние, но и дальние перспективы, ориентироваться на их достижение, причем не только в направлении «от ближнего - к дальнему», но и наоборот - «через дальнее - к ответственному и всестороннему освоению ближнего», то есть проведение конкретных исследований всегда должно осознаваться в контексте того, что решение $u$ отдаленных задач также актуально, как и текущих.

В этом аспекте примером подлинно ответственной научной позиции является деятельность С.П. Королева - руководителя творческого, научного и производственного коллектива, совершившего исторический рывок в отечественной космонавтике. Несмотря на давление военных, которые требовали решать в первую очередь вопросы обороны страны, то есть реагировать на задачи сегодняшнего дня, Королев никогда не упускал из виду стратегической цели - космических перспектив СССР. Формирование субъектов современной науки - это способность ученых постоянно выходить за рамки современности, осваивать будущее с позиций единства науки, культуры и гуманизма.

Основой освоения метасубъектного пространства являются не просто технологии или особые методы обучения, но в первую очередь - межсубъектный диалог взаимодействие научных коллективов, как и отдельных сотрудников в одном коллективе на основе того нормативно-ценностного содержания (или контекста), в котором открывается само метасубъектное пространство действий, оценок, принятия решений, осуществления выбора и др. 
Таким образом, основанием развития современного субъекта науки является освоение всей полноты содержания и нормативности постнеклассической рациональности, в которую входят:

1) Тесная связь субъекта с объектом познания. процесс.

А. Познание как субъект-субъектный

В. Рефлексия относительно ценностного измерения получаемого знания.

С. Саморазвивающийся характер познаваемых систем.

2) Окончательное преодоление «гносеологической робинзонады».

А. Необходимость соотношения трех форм субъектности: личности, коллектива, института.

В. Осознание диалогизма как основания бытия человека, необходимости опоры на принцип сотрудничества.

C. Закрепление понимания как метода современной науки.

3) Проблематизацию освоения знания.

А. Связь фундаментальных и прикладных исследований, технологизация

В. Анализ рискогенности знания.

Bce описанные аспекты выражают тенденцию не к снятию субъекта, а к его целостному пониманию. Во-первых, трансформируется современная наука: она существует как диалог на стыке сфер науки и культуры. Во-вторых, основания социального бытия людей все чаще раскрывается в контексте понятий сотрудничества, в противовес представлениям о хаосе и конкуренции, как залоге развития. В-третьих, актуализируется вопрос о единстве субъектной формы бытия общества. Наука все чаще воспринимается как ресурс, определяющий характер развития общества в стратегической (фундаментальные исследования), тактической (прикладные исследования) и в практической (продуцирование технологий, внедрение в производство) областях. В такой ситуации она не может восприниматься как изолированная область социума, процессы в которой никаким образом не отражаются на ее социокультурной среде. Институциональное признание подобного статуса современной науки на государственном уровне является симптомом того, что ее вышеописанные характеристики уже стали явью и необходимость выйти на соответствующие позиции - это неоспоримый факт. «Научно-технологическое развитие Российской Федерации - трансформация науки и технологий в ключевой фактор развития России и обеспечения способности страны эффективно отвечать на большие вызовы» [12] - с такого тезиса начинается Стратегия научно-технологического развития Российской Федерации, и подобное планирование предполагает необходимость передовых социальных трансформаций, которые выводят науку и ее субъект за собственные пределы. Однако описание актуальности развития субъекта современной науки это лишь преддверие поиска направлений технологического воздействия на науку.

В нашем подходе социальные технологии - это направления, регулирующие опыт и содержание деятельности субъектов исследования, которые осуществляются в пространстве метасубъекта. Здесь совмещается диалог, сотрудничество, с одной стороны, и нравственно-культурное, социально-гражданское развитие самих ученых - с другой. Основная деятельность ученых проходит в научных коллективах, представляющих собой достаточно сложное субъектное образование, в котором существует несколько уровней субъектности: личностный, коллективный, организационный, институциональный, профессионально-квалификационный и др. Поэтому возникают и различные внутриколлективные отношения субъектов, и межколлективные научные связи. Но эта групповая субъектность в науке сохраняет личностный характер. Соавторство всегда персонифицировано, то есть личное участие в совместном научном исследовании явно; научный кружок представляет собой малую социальную группу, лишенную какой бы то ни было анонимности. Сохраняется эта ситуация и в такой устойчивой форме научного сообщества, как научная школа, хотя во многом «лицом» группы выступает лидер или преемник. Однако научная группа - это также не предельный уровень субъектности в науке. Все многообразные научные сообщества и индивиды, включенные в них, находятся в универсальной среде - науке как социальном институте, данном нам в форме организаций и учреждений.

Важно подчеркнуть, что развитие субъектов научной деятельности - не толь- 
ко расширение их мировоззрения и усиление значения социальной ответственности. Этисубъекты меняют научную среду: она не только становится неотъемлемой частью социальной жизни и требований общества, но и задает параметры и нормы системы образования, выступает как «штаб» передовых идей и технологий, как носитель высоких отечественных традиций в науке. Такими интегральными основами соединения науки и культуры, науки и общества, а также являются социальные технологии, которые в данном аспекте выявляют скрытый потенциал самого общества, его связей, лишь частично освоенный и «объективированный» академической наукой.

Поэтому дальнейшие исследования процесса и содержания, необходимых для развития субъектов современной науки, являются актуальными и перспективными.

\section{СПИСОК ЛИТЕРАТУРЫ}

1. Гадамер, Х.-Г., Истина и метод: Основы философской герменевтики : пер. с нем. / Х.-Г. Гадамер ; общ. ред. и вступ. ст. Б. Н. Бессонова. - М. : Прогресс, 1988. - 704 с.

2. Горохов, В. Г. Понятие «технология» в философии техники и особенность социально-гуманитарных технологий / В. Г. Горохов // Epistemology \& Philosophy of Science. - 2011. - № 2. - С. 110-123.

3. Гусева, И. И. О современных тенденциях дисциплинарной организации социально-гуманитарных наук / И. И. Гусева // Исторические, философские, политические и юридические науки, культурология и искусствоведение. Вопросы теории и практики. - 2017. - № 12 (86), ч. 3. C. 32-35.

4. Есина, О. Ю. Проблема эмпирического субъекта и типы рациональности / О.Ю.Есина // Известия Саратовского университета. Серия: Философия. Психология. Педагогика. - 2011. - Т. 11, вып. 3. - С. 35-37.

5. Иванов, В. Н. Инновационные социальные технологии государственного и муниципального управления / В. Н. Иванов, В. И. Патрушев. - М. : Экономика, 2001. - 327 с.

6. Мертон, Р. Социальная теория и социальная структура / Р. Мертон. - М. : АСТ : АСТ МОСКВА : ХРАНИТЕЛЬ, 2006. $-873 \mathrm{c}$.

7. Огурцов, А. П. Интерсубъективность как проблема философии науки / А. П. Огурцов // Философия науки и техники. -2009. - № 1. - С. 235-246.
8. Петракова, Н. В. Структура межчеловеческого отношения в философии М. Бубера / Н. В. Петракова // Вестник БГУ. - 2017. - № 5. - С. 109-116.

9. Социологический энцилопедический словарь / под ред. Г. В. Осипова. - М. : НОРМА, 2000. $-482 \mathrm{c}$.

10. Степин, В. С. Научная рациональность в техногенной культуре: типы и историческая эволюция / В. С. Степин // Вопросы философии. - 2012. № 5. - Электрон. текстовые дан. - Режим доступа: http://vphil.ruindex.php?option=com_content \& task =view\&id=533\&Itemid=5 (дата обращения: 18.09.2018).

11. Тулмин, С. Человеческое понимание : пер. с англ. / С. Тулмин ; общ. ред. и вступ. ст. П. Е. Сивоконя. - М. : Прогресс, 1984. - 327 с.

12. Указ Президента РФ от 01.12.2016 № 642 «О Стратегии научно-технологического развития Российской Федерации». - Доступ из справ.-правовой системы «КонсультантПлюс» (дата обращения: 18.09.2018).

\section{REFERENCES}

1. Gadamer H.G. Istina i metod: Osnovy filosofskoy germenevtiki [Truth and Method: Fundamentals of Philosophical Hermeneutics]. Moscow, Progress Publ., 1988. 704 p.

2. Gorokhov V.G. Ponyatie «tekhnologiya» V filosofii tekhniki i osobennost sotsialno-gumanitarnykh tekhnologiy [The Concept of Technology in the Philosophy of Technology and the Peculiarity of SocioHumanities Technologies]. Epistemology \& Philosophy of Science, 2011, no. 2, pp. 110-123.

3. Guseva I.I. O sovremennykh tendentsiyakh distsiplinarnoy organizatsii sotsialno-gumanitarnykh nauk [About Modern Tendencies of the Disciplinary Organization of Social Sciences and Humanities]. Istoricheskie, filosofskie, politicheskie i yuridicheskie nauki, kulturologiya i iskusstvovedenie. Voprosy teorii i praktiki, 2017, no. 12 (86), part 3, pp. 32-35.

4. Esina O.Yu. Problema empiricheskogo subyekta i tipy ratsionalnosti [The Problem of the Empirical Subject and the Types of Rationality]. Izvestiya Saratovskogo universiteta. Seriya: Filosofiya. Psikhologiya. Pedagogika, 2011, no. 11, iss. 3, pp. 35-37.

5. Ivanov V.N., Patrushev V.I. Innovatsionnye sotsialnye tekhnologii gosudarstvennogo $i$ munitsipalnogo upravleniya [Innovative Social Technologies of State and Municipal Management]. Moscow, Ekonomika Publ., 2001. 327 p.

6. Merton R. Sotsialnaya teoriya i sotsialnaya struktura [Social Theory and Social Structure]. Moscow, AST Publ., 2006. 873 p.

7. Ogurtsov A.P. Intersubyektivnost kak problema filosofii nauki [Intersubjectivity as a Problem 
of the Philosophy of Science]. Filosofiya nauki $i$ tekhniki, 2009, no. 1, pp. 235-246.

8. Petrakova N.V. Struktura mezhchelovecheskogo otnosheniya v filosofii M. Bubera [The Structure of InterHuman Relations in the Philosophy of M. Buber]. Vestnik $B G U, 2017$, no. 5, pp. 109-116.

9. Osipov G.V., ed. Sotsiologicheskiy entsilopedicheskiy slovar [Sociological Encyclopedic Dictionary]. Moscow, Norma Publ., 2000. 482 p.

10. Stepin V.S. Nauchnaya ratsionalnost v tekhnogennoy kulture: tipy $\mathrm{i}$ istoricheskaya evolyutsiya [Scientific Rationality in Anthropogenic Culture: Types and Historical Evolution]. Voprosy filosofii, 2012, no. 5. URL: http://vphil.ru/index.php?option=com_content\& task=view\&id $=533 \&$ Itemid $=5$.

11. Tulmin S. Chelovecheskoe ponimanie [Human Understanding]. Moscow, Progress Publ., 1984. 327 p.

12. Ukaz Prezidenta RF ot 01.12.2016№ $642 « O$ Strategii nauchno-tekhnologicheskogo razvitiya Rossiyskoy Federatsii» [Decree of the President of the Russian Federation of 1 December 2016 No. 642 'About the Strategy of Scientific and Technological Development of the Russian Federation']. Access from Reference Legal System 'KonsultantPlyus' (accessed 18 September 2018).

\section{Information about the Author}

Oleg S. Smoligovets, Postgraduate Student, Department of Philosophy, Volgograd State University, Prosp. Universitetsky, 100, 400062 Volgograd, Russian Federation, feanorik@mail.ru.

\section{Информация об авторе}

Олег Сергеевич Смолиговец, аспирант кафедры философии, Волгоградский государственный университет, просп. Университетский, 100, 400062 г. Волгоград, Российская Федерация, feanorik@mail.ru. 